Clausen, Jane K. (1955). J. gen. Microbiol. 12, 496-502

\title{
Observations on the Carbohydrate Metabolism of the Flagellate Strigomonas oncopelti
}

\author{
By JANE K. CLAUSEN \\ Lister Institute of Preventive Medicine, London, S.W.1, and \\ Institute of Animal Physiology, Babraham, Cambridge
}

SUMMARY : Cultures of Strigomonas oncopelti multiplied more rapidly and a higher peak population was reached when glucose was added to the peptone medium. The rate of glucose consumption varied during the growth cycle; the maximum rate recorded was $90 \mu \mathrm{g} . / 10^{8}$ organisms $/ 24 \mathrm{hr}$. The breakdown of glucose resulted in the production of acetic, succinic, probably lactic, and an unidentified non-volatile acid.

Strigomonas oncopelti, a flagellate belonging to the family Trypanosomidae, is a parasite of latex plants and is transmitted by plant bugs. It can be readily cultivated in peptone water. Noguchi (1926) and Lwoff (1934) showed that the organism can metabolize glucose. The experimental work to be described shows the difference between the growth characteristics of $S$. oncopelti in the presence and absence of glucose, and demonstrates how the rate of glucose consumption varies during the growth cycle. The glucose breakdown and accompanying acid production are compared with those of other members of the family Trypanosomidae.

\section{METHODS}

Cultivation. Stock cultures of a bacteria-free strain of Strigomonas oncopelti received from Dr A. Lwoff were grown in $8 \mathrm{ml}$. volumes of $3 \%$ Oxoid peptone (Oxo Ltd.) at $\mathrm{pH} \mathrm{7.4}$ containing $0.5 \% \mathrm{NaCl}$. The medium was sterilized by autoclaving at $15 \mathrm{lb}$./sq.in. for $20 \mathrm{~min}$. The organisms were grown at room temperature and subcultures were made every 4-7 days. For the experimental work the organisms were grown in $3 \%$ Oxoid or Difco proteose peptone containing $0.5 \% \mathrm{NaCl}$.

Counting. The cultures were mixed gently before sampling as the organisms tended to form a film at the surface. Samples of $1 \mathrm{ml}$. were fixed with a drop of formalin. The organisms adhered together in rosettes in the cultures and the fixed samples were therefore shaken vigorously before counting in order to break up the clumps. Duplicate counts were made on each sample in a Neubauer haemocytometer, a minimum of $\mathbf{3 0 0}$ organisms being counted, and the mean of the results then taken.

$\mathrm{pH}$ measurement. A Cambridge bench type $\mathrm{pH}$ meter (Cambridge Instrument Co. Ltd.) was used which was standardized with buffers of $\mathrm{pH} 4 \cdot 0$ and $\mathbf{9 \cdot 2}$.

Glucose estimation. Glucose was estimated by the method of Somogyi (1937). 
A sample of $1 \mathrm{ml}$. of medium was diluted with $10 \mathrm{ml}$. of water and deproteinized by adding $1 \mathrm{ml}$. of each of $7 \%(\mathrm{w} / \mathrm{v}) \mathrm{CuSO}_{4} .5 \mathrm{H}_{2} \mathrm{O}$ and of $10 \%$ $(\mathrm{w} / \mathrm{v})$ sodium tungstate. After removal of the precipitate by centrifugation $1 \mathrm{ml}$. of the supernatant fluid was diluted with $4 \mathrm{ml}$. of water before addition of the copper reagent. Duplicate determinations were carried out on each sample.

Extraction of organic acids from the medium. The medium $(165 \mathrm{ml}$.) was adjusted to $\mathrm{pH} 1 \cdot 0-1 \cdot 5$ with $5 \mathrm{~N}-\mathrm{H}_{2} \mathrm{SO}_{4}$ and the organic acids extracted with ether in a continuous extraction apparatus. The ethereal extract was shaken with a slight excess of alkali $(0 \cdot 1 \mathrm{~N}-\mathrm{NaOH})$ and the aqueous solution containing the acids was concentrated to approximately $25 \mathrm{ml}$. The steam-volatile and non-volatile acids were separated by steam distillation of the acidified solution $\left(\mathrm{pH} \mathrm{1.0-1.5)}\right.$ and the distillate was titrated under $\mathrm{CO}_{2}$-free conditions, using phenolphthalein as indicator. The neutralized distillate was concentrated and kept for chromatographic analysis.

In order to avoid the presence of large amounts of inorganic salt the nonvolatile acids were re-extracted with ether from the solution remaining after steam distillation, and finally obtained as their sodium salts by shaking the ether with the minimum amount of $0.02 \mathrm{~N}-\mathrm{NaOH}$ required for complete extraction and then evaporating the solution to dryness.

Analysis of volatile fatty acids. The volatile fatty acids were analysed by gas/liquid partition chromatography (James \& Martin, 1952).

Analysis of non-volatile acids. The non-volatile acids were examined by paper chromatography using the general technique of Long, Quayle \& Stedman (1951). The following solvent systems were used: (1) ethanol 80 vol. + aqueous ammonia, 0.88 sp.gr., 4 vol. + water 16 vol.; (2) ethanol 90 vol. + aqueous ammonia, 0.88 sp.gr., 5 vol. + water 5 vol. In some instances the papers were sprayed with the indicator recommended by Duncan \& Porteous (1953).

\section{EXPERIMENTAL}

Growth of Strigomonas oncopelti in the presence and absence of glucose

Two growth curves were constructed for Strigomonas oncopelti. For the first the organism was grown in peptone (Difco proteose) water alone and for the second in peptone water $+0.5 \%$ glucose. The peptone medium without added glucose contained the equivalent of $25 \mathrm{mg}$. reducing sugar $/ 100 \mathrm{ml}$. In both instances the procedure was as follows. The medium $(500 \mathrm{ml}$.) was sterilized in a flask. As controls, two samples of $8 \mathrm{ml}$. were withdrawn before inoculation. The $\mathrm{pH}$ value and glucose content of one sample were determined at the beginning of the experiment. The second sample was incubated with the inoculated medium, the $\mathrm{pH}$ value and glucose content being estimated at the end of the experiment. The flask of medium was inoculated with a 5-day culture of $S$. oncopelti to give an initial count of $c .500,000$ organisms $/ \mathrm{ml}$. The inoculum had been grown in peptone water without added glucose. After inoculation the medium was distributed into test-tubes in $8 \mathrm{ml}$. volumes. Immediately afterwards four tubes were withdrawn for counting and for $\mathrm{pH}$ 
and glucose estimations. The remaining tubes were left at room temperature $\left(\right.$ c. $\left.20^{\circ}\right)$ in the dark. Four tubes were withdrawn daily until the organisms began to die. From each tube $1 \mathrm{ml}$. was fixed for counting and $3 \mathrm{ml}$. used for the $\mathrm{pH}$ estimation. The remainder of the culture was then centrifuged and the supernatant stored at $-10^{\circ}$ for subsequent glucose estimations.

The results of the pH measurements and the counts are illustrated in Figs. 1 and 2; each value used is the average for the four parallel tubes. In the absence of glucose (Fig. I) the peak population of c. $25 \times 10^{6} \mathrm{organisms} / \mathrm{ml}$. was reached on the eighth day. This represented $5 \cdot 3$ generations; during the most rapid period of multiplication the generation time was $14 \mathrm{hr}$. By the ninth day some of the organisms had died and the counts were discontinued.

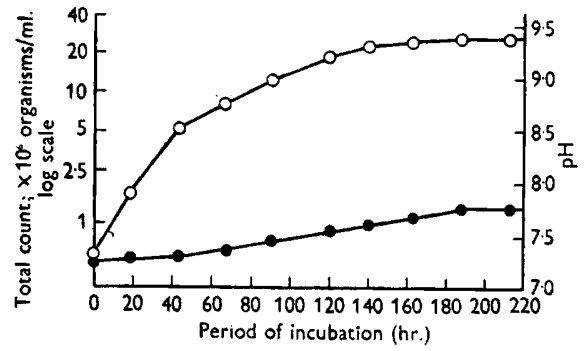

Fig. 1

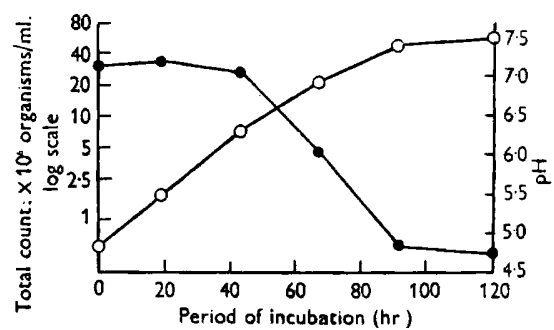

Fig. 2

Fig. 1. Growth and $\mathrm{pH}$ curve of $S$. oncopelti in the absence of glucose. $0-0$, growth; $\longrightarrow$ pH curve.

Fig. 2. Growth and pH curve of $S$. oncopelti in the presence of glucose. $0-0$, growth; $\bullet-\bullet$ pH curve.

When $0.5 \%$ glucose was present in the medium the growth curve was different from that obtained without glucose (Fig. 2); the organisms multiplied more rapidly, the shortest generation time was $12 \mathrm{hr}$., a higher peak population was reached and the cultures began to die sooner. The peak population of $55 \times 10^{6}$ organisms $/ \mathrm{ml}$. occurred on the fifth day; this represented 6.5 generations. Dead organisms then began to appear in considerable numbers and the counts were discontinued.

It appeared, therefore, that although glucose was not an essential constituent of the medium it increased the rate of multiplication and a higher peak population was reached in its presence. The earlier death of the cultures in glucose peptone may possibly be associated with the low $\mathrm{pH}$ value of the medium resulting from the breakdown of glucose. When glucose was not added to the medium the $\mathrm{pH}$ value increased steadily from $7 \cdot 3$, reaching $7 \cdot 8$ on the eighth day (Fig. 1). The $\mathrm{pH}$ value of the medium containing $0.5 \%$ glucose fell from $7 \cdot 2$ to $4 \cdot 7$ by the fifth day (Fig. 2). After the organisms began to die the $\mathrm{pH}$ value rose again slowly and reached $\mathrm{pH} 5 \cdot 1$ on the tenth day. During the growth of the cultures the $\mathrm{pH}$ value of the uninoculated control remained constant. 


\section{Glucose consumption}

Glucose estimations were carried out on one of the four tubes withdrawn each day. During the period of the experiment the apparent reducing-sugar content of the uninoculated control increased by $40 \mathrm{mg} . / 100 \mathrm{ml}$., presumably due to concentration by evaporation. The rate of glucose consumption calculated from the glucose estimations is shown in Fig. 3. The rate of glucose consumption was calculated from the mean of the counts at the beginning and end of each $24 \mathrm{hr}$. period and the quantity of glucose which disappeared from the medium during the period. The rate of glucose consumption was not constant throughout the growth cycle (Fig. 3), but increased while the organisms were multiplying rapidly and decreased rapidly as the division rate slowed down. By $120 \mathrm{hr}$., when the population had reached $55 \times 10^{6}$ organisms $/ \mathrm{ml}$. and the $\mathrm{pH}$ value had fallen to $4 \cdot 7$, only $25 \mathrm{mg}$. glucose $/ 100 \mathrm{ml}$. was left in the medium. The maximum rate of glucose consumption recorded was $90 \mu \mathrm{g} . / 10^{6}$ organisms $/ 24 \mathrm{hr}$. This represented a ninefold increase in rate during the time the organisms were multiplying.

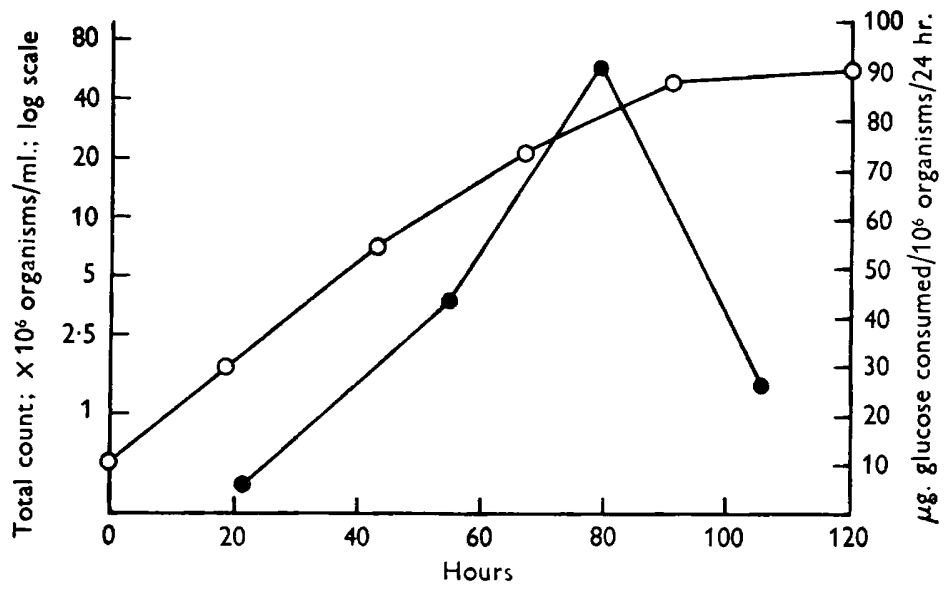

Fig. 3. Growth and glucose consumption of $S$. oncopelti. $\mathrm{O}-\mathrm{O}$, growth; - - , glucose consumption.

The acids produced from the breakdown of glucose

Glucose peptone (Oxoid) medium (250 ml.) was inoculated with a 5-day culture of Strigomonas oncopelti togive an initial count of $c .500,000$ organisms $/ \mathrm{ml}$. and was left at room temperature $\left(c .20^{\circ}\right)$ in the dark for 4 days; an equal volume of uninoculated glucose peptone was left for the same period as a control. After growth the organisms were separated by centrifugation and the supernatant fluid was clarified with a Seitz filter. Samples of the volatile and non-volatile organic acids present in both uninoculated and used media were prepared as previously described. Examination of these samples showed an increase of both volatile and non-volatile acids in the used medium. The increase in volatile acid was entirely due to an increase in acetate (Table 1). 
Examination of the samples of non-volatile acids by paper chromatography showed that lactic acid was present in both uninoculated and used medium, while succinic acid and another unidentified acid were present in used medium only. The unidentified spot was not any of the following: oxalic, citric, tartaric, malonic, malic, maleic, adipic, pimelic, pyruvic, glutaric, glycolic, fumaric, crotonic, acrylic or $\beta$-hydroxybutyric acids. In earlier experiments the nonvolatile acid samples were examined for lactic acid by the method of Friedemann \& Graeser (1933); this method is not specific for lactic acid, but the large apparent increase (threefold) of lactic acid in the used medium strongly suggests that it was produced as an end product. The breakdown of glucose by Strigomonas oncopelti results, therefore, in the production of acetic, succinic, and probably lactic acids, and an unidentified non-volatile acid.

Table 1. Volatile fatty acid content of glucose peptone medium.

(1) Uninoculated, (2) after growth of Strigomonas oncopelti

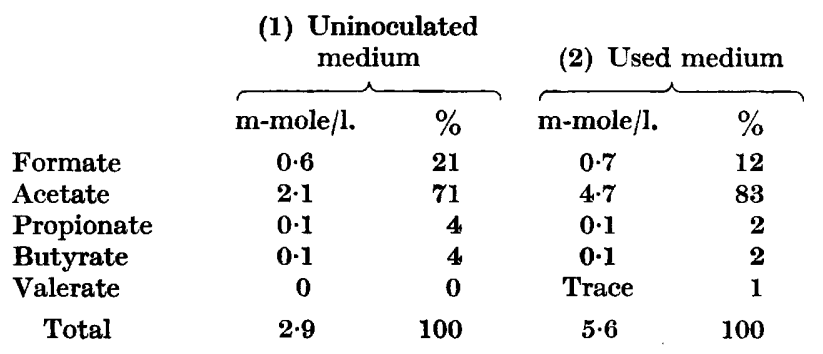

\section{DISCUSSION}

The carbohydrate metabolism of cultivated forms (invertebrate host stage) of trypanosomes and of other members of the family which have been grown in vitro has not been studied as thoroughly as that of the blood stream forms of trypanosomes (from the vertebrate host). However, the carbohydrate metabolism of Strigomonas oncopelti shows some similarities to that of the other members of the Trypanosomidae grown in vitro. Some of the species which have been studied are not dependent on a supply of glucose. Trypanosoma cruzi (von Brand, Tobie, Kissling \& Adams, 1949), T. gambiense and T. rhodesiense (Tobie, von Brand \& Mehlman, 1950) have been grown without added glucose, although glucose was consumed when it was available. It is interesting that glucose consumption by the blood stream form of T. cruzi cannot be detected (von Brand et al. 1949) while the blood stream forms of $T$. gambiense and $T$. rhodesiense have a much higher rate of consumption than the cultivated forms (von Brand \& Tobie, 1948). Strigomonas media and $S$. parva have been grown in peptone medium without added glucose (Lwoff, 1936), and Leptomonas ctenocephali did not utilize glucose under aerobjc conditions even when it was present (Lwoff, 1934). Other organisms which have been cultivated in vitro and shown to consume glucose include several species of Leishmania (Salle \& Schmidt, 1928; Chang, 1948). 
The rate of glucose consumption by Strigomonas oncopelti varies considerably during the growth cycle, the rate increasing while the generation time is short, and falling rapidly when multiplication ceases; Fulton \& Joyner (1949) found similarly that young cultures of Leishmania donovani used more glucose than old cultures.

The incomplete oxidation of glucose which results in the production of a number of organic acids appears to be characteristic of the members of the Trypanosomidae so far investigated. Strigomonas oncopelti produced acetic, succinic and probably lactic acids, and also an unidentified non-volatile acid. Formic, acetic, pyruvic, lactic, oxalic and succinic acids have been identified as end products of glucose breakdown by various trypanosomes and leishmanias (von Brand, 1951); the unidentified acid produced by $S$. oncopelti is not one of these. As $S$. oncopelti is a parasite of plants it might well be expected to show some different characteristics from the parasites of vertebrates.

Most of the work was carried out during the tenure of a studentship from the Medical Research Council. I should like to thank Dr Muriel Robertson, F.R.S., for her guidance and help, and I am grateful to Dr E. F. Annison for analysing the volatile fatty acids and for the lactic acid estimations.

\section{REFERENCES}

Chang, S. L. (1948). Studies on haemoflagellates. IV. Observations concerning some biochemical activities in culture, and respiration of three species of Leishmania and Trypanosoma cruzi. J. infect. Dis. 82, 109.

Duncan, R. E. B. \& Porteous, J. W. (1953). The identification and determination of the lower straight-chain fatty acids by paper partition chromatography. Analyst, 78, 641.

Friedemann, T. E. \& Graeser, J. B. (1933). The determination of lactic acid. J. biol. Chem. 100, 291.

Fulton, J. D. \& Joyner, L. P. (1949). Studies on Protozoa. Part I. The metabolism of Leishman-donovan bodies and flagellates of Leishmania donovani. Trans. R. Soc. trop. Med. Hyg. 43, 273.

James, A. T. \& MARTIN, A. J. P. (1952). Gas-liquid partition chromatography: the separation and micro-estimation of volatile fatty acids from formic acid to dodecanoic acid. Biochem. J. 50, 679.

Long, A. G., Quayle, J. R. \& Stedman, R. J. (1951). The separation of acids by paper partitition chromatography. J. Chem. Soc. p. 2197.

LwoFf, A. (1934). Die Bedeutung des Blutfarbstoffes für die parasitischen Flagellaten. Zbl. Bakt. (1. Abt. Orig.), 130, 498.

Lwoff, M. (1936). Le pouvoir de synthèse des trypanosomides des muscides. C.R. Soc. Biol., Paris, 121, 419.

NoguchI, H. (1926). Comparative studies of herpetomonads and leishmanias. II. Differentiation of the organisms by serological reactions and fermentation tests. J. exp. Med. 44, 327.

Salle, A. J. \& Schmidt, C. L. A. (1928). The metabolism of Leishmania tropica. J. infect. Dis. 43, 378.

SomogYI, M. (1937). A reagent for the copper-iodometric determination of very small amounts of sugar. J. biol. Chem. 117, 771 .

Tobie, E. J., von Brand, T. \& Mehlman, B. (1950). Cultural and physiological observations on Trypanosoma rhodesiense and Trypanosoma gambiense. J. Parasit. 36, 48. 
von Brand, T. (1951). In Biochemistry of Protozoa. Ed. Lwoff, A. Vol. 1, p. 193. New York: Academic Press.

von Brand, T. \& Tobie, E. J. (1948). Further observations on the influence of cyanide on some trypanosomes. J. cell. comp. Physiol. 31, 49.

von Brand, T., Tobie, E. J., Krssurng, R. E. \& Adams, G. (1949). Physiological and pathological observations on four strains of Trypanosoma cruzi. J. infect. Dis. 85, 5.

(Received 25 November 1954) 